tra-indicação, é feita uma observação, à página 102, mencionando que os enormes benefícios arrolados são obtidos nas empresas que já possuem, antes da adesão ao IIT/TQC, uma boa administração.

Em conclusaa, o trabalho aqui resenhado constitui valiosa advertência às empresas quanto a necessidade de progredir continuamente e de mudar sempre, para sobreviver. Deve ser encarado como uma palestra de conscientização introdutória, para as diretorias que desejam se iniciar no assunto. É mais uma voz a se juntar ao grande coro que retransmite com entusiasmo a nova mensagem vinda do Oriente, e cujos temas - inovação, treinamento, motivação, conscientização, flexibilidade e participação prometem às empresas a salvação e o êxito. $]$

\section{A REBELDIA DO TRABALHO (O CONFRONTO OPERÁRIO NO ABC PAULISTA: AS GREVES DE 1978/80)}

\section{RICARDO ANTUNES}

Săo Paulo/Campinas, Editora Ensaio/Editora da UNICAMP, 1988,220 páginas.

\section{Por Afrânia Mendes Catani}

Professor na Faculdade de Educação da Universidade de Săo Paulo.

O objetivo do livro de Ricardo Antunes, professor de Sociologia do Trabalho na Universidade Estadual de Campinas e Diretor do Arquivo Edgard Leuenroth (Centro de Pesquisa e Documentação Social) da mesma Universidade, é o de apreender o significado das greves metalúrgicas desencadeadas pelo $\mathrm{ABC}$ Paulista entre 1978 e 1980, momento marcado pela realizaçäo de expressivo confronto operário.

Com a finalidade de estudar as greves metalúrgicas do período, Antunes analisa, na primeira parte, a greve em si, em sua efetividade, processualidade e concretude, tentando captar o sentido imanente dessas greves, suas causalidades e seus componentes teleologicos. Através do estudo das greves nas fábricas em maio de 1978 às greves gerais das Assembléias Plebiscitárias em 1979 e 1980, buscou-se apreender este fenomeno em seu ir-sendo, em seu fazerse, em seu movimento, apontando seus avanços, positividades e limitaçōes (p.8).

Para Antunes, essas greves metalúrgicas encontraram sua causalidade básica na luta contra a superexploração do trabalho. "Ainda que diversas reivindicaçöes estivessem presentes, o que centralmente motivou a eclosäo da ação grevista foi a necessidade de contrapor-se ao arrocho salarial. $E_{\text {f }}$ assim, comportando uma pauta retvindicatória de natureza predominantemente economica, as greves metalurgicas assumiram, desde seu desencadear, nifida dimensão politica, expressa no confronto que efetioxaram contra a base material e a superestrutura juridico-política da autocracia bur$g^{u e s a^{\prime \prime}}$ (p. 167; grifos do original).

As paralisações metalúrgicas foram o resultado da ação espontânea dos trabalhadores, sendo que a presença do sindicato operärio (em especial em Săo Bernardo) foi relevante ao longo de toda a atuaçäo do proletariado metalúrgico vinculado à indústria automobilística. Entretanto, "as três greves foram marcadas por singularidades que, por vezes, a diferenciavam quanto a aspectos de sta efetruidade (preparação. desencadeamento, ação teleológica, resultados $e$ desdobramentos)" (p. 167). No entender de Antunes, "enquanto as Greves de Maio de 1978 assumiram a forma de paralisações parciais, por fabricas, com os trabalhadores de bracos cruzados, mäquinas paradas' dentro das empresas, desencadeando uma ação que oscilou entre a herança de una fase de resistência, defensina, e um ressurgir com sinnis de ofensividade" (p. 167-168), a Greve de Massas de 1979 "assumiu a feiçäo de uma greve geral metalusgica do ramo antomobilistico, cujo cotidiato foi marcado pela realização de assembleias gerais plebiscitarias, comportando um conteudo acentuadamente ofensivo" (p. 168). A greve geral metalúrgica de 1979, apesar de caracterizar-se pela espontaneidade, contou também com a presença atuante do sindicato operário e, da mesma forma que a greve de 1978 , foi vitoriosa para os trabalhadores. "Em contrapartida foram duas significativas derrotas para o capital $e$ o seu Estado politico, confrontos que repudawam diretamente a dimensão salarial de sua política econômica - o arrocho - e desnudavam o verdadeiro conteudo do processo de autoreforma do poder" (p. 168).

Todavia $a_{x}$ em 1980, houve uma alteração significativa. Assumindo tamberm a forma de greve geral desde o seu desencadeamento, com os operários realizando praticamente todos os dias assembléias gerais plebiscitárias, "a açâo metalurgica foi perdendo, ao longo dos seus quarenta $e$ um dias, a sua pujança inicial (..) Econowica na sua causação mais imediata, política na sua significação mis profunda, a Greve Geral Metalungica de 1980 năo conseguiu, entretanto, converter-se em vitoria jara os trabalhadores. $O$ Estado bonapartista ja havia detectado, nesta luta social, seu mais dificit contendor" (p. 168-169). E Antunes detecta com precisão a aç̃̂̃o política do Estado nesse momento, ao perceber que caberia a ele, em sua lógica ditatorial, "desestruturar este pólo propulsionador das açöes reivindicatónias das massas. E, lamentavelmente, o movimento desencadeado pelo opera- 
riado metalúrgico näo foi capaz de romper com essa logica do poder politico do capital". Além disso. acrescenta, "a ausência de wma direção politica consciente, dotada de independência térica $e$ ideologica, impossibiliton a visualização plena da confextualizaçâo social e politica vigente, levando o mozimento à derrota" (p. 169; grifos do original).

Na segunda parte de $A$ Rebeldia do Trabalho, o autor faz uma caracterização do proletariado metalúrgico do $\mathrm{ABC}$ paulista, avançando também "na tematizaçüo dos elementos causais que possibilitaram o ressurgimento grevista a partir do pólo metulúrgico vinculado ao ramo automobilisti$c^{\prime \prime}(p, 8)$. A irrupção da crise econômica, cujos sintomas transpareceram já no final de 1973 (com o esgotamento do chamado "milagre brasileiro"), "ao aflorar a necessidade de reordenar e recompor os diversos interesses das frações dominantes aue se articulavam em torno do tripé, capital monopolista externo, capital monopolista privado nacional e setor produtivo estatal", atingiu diretamente a forma pela qual o aparato estatal se estruturava. Competia ao aparato estatal através de um rearranjo do bloco no poder "forjar alternativas que näo trouxessem ônus em demasia para as fraçóes monopolistas dominantes". Nesse sentido, a crise assumia uma dimensão política explícita (p.112). Aproveitando-se das metamorfoses do poder político bonapartista $e$ das dissençóes que afloravam no bloco no poder, deu-se "o ressurgimento do movimento operário, desmistificando o projeto 'aberturista', desnudando seu carater de transição 'pelo alto'; por' dentro do poder ditatorial. Por isto, constitui-se em obstáculo que forçou o prolongamento da estratégia polticica de auto-reforma do poder politico e da dominação autocrática" (p. 126).

Nas conclusōes, Ricardo Antunes desenvolve as categorias fundamentais presentes no fenomeno social da greve, apontando os nexos existentes entre os processos efetivos de greves e suas manifestaçóes ao nível da consciência operária nas greves de 1978 e 79 e, também, mostra as limitaçöes presentes na greve de 1980. Encerra com uma reflexão teórica acerca das conexões existentes entre os processos efetivos de greve e o desenvolvimento da consciência do ser social que trabalha.

Nas palavras de Florestan Fernandes, autor da "Apresentaçăo", o livro de Ricardo Antunes retoma, em conjunto, "uma vasta documentação sobre as Greves do $A B C$ e lança um desafio. De um Lado, os operários, ao negar a empresa $e$ o capital, negam o govermo ditatorial e sua politica econômica (..). De outro lado, estä o desafio. Os operúrios chegaram atê at (...). A fronteira agora é mais ampla (...), é preciso derrotar simultaneamente o arro cho dos salátios e o solapamento dos padrôes de soltdariedade de classe. Esses fatos são cruciais. Eles colocam o Brasil no limiar de uma nova era." $\square$

\section{MANUAL DE PREPARAÇÄO DE ESTUDOS DE VIABILIDADE INDUSTRIAL}

\author{
UNIDO - ORGANIZAÇÃO PARA O \\ DESENVOLVIMENTO INDUSTRIAL DAS NAÇÖES \\ UNIDAS \\ Traduzido do inglès, Manual for the \\ Preparation of Industrial Feasibility Studies (1987), \\ por Antonio Norival Brito Rabelo. \\ São Paulo, Editora Atlas, 1987.

\section{Por Kurt Ernst Weil} \\ Professor no Departamento de Administraçăo de \\ Produçăa e Operaçōes Industriais da \\ EAESPIFGV.
}

Como se nota, trata-se de um livro escrito por tum grupo, sabendo-se pelos agradecimentos e pela bibliografia que houve o uso de diversas publicações prévias da ONU e da UNIDO. Apeșar da predominância de autores árabes $\mathrm{e}$ da Índia, o livro mantém uma excelente unidade e é realmente de uso geral - independente do país onde é aplicado, mesmo quando não é do Terceiro Mundo. A existência da colaboração de Friederich Giersig deu um toque de literatura alemã à bibliografia, que geralmente é em inglês e francềs, o que é ótimo,

Gostei muito do livro, acho-o ótimo como literatura e livro-texto na área, mas precisa ser complementado por no mínimo cinco tipos de publicações sobre os seguintes tópicos:

$1 \%$ Ecologia, Meio Ambiente e Poluição Ambiental. As referências das páginas 108 , impactos ambientais, e página 119 , pocira e fumaça, são insuficientes;

$2^{\circ}$ Financiamento de projetos (pág. 176) referências insuficientíssimas (págs. 112 e 199);

$3^{2}$ Engenharia Econômica: retorno (pág. 211 a 227);

4. Teoria e prática internacional de patentes, royalties, marcas etc. só são mencionados de leve;

$5^{2}$ Custo-benefício, análise e prática.

A rica bibliografia dă livros em abundância para todas essas áreas, mas nada em português. No entanto, existem livros para todas as necessidades em português.

Talvez não ter feito uma bibliografia brasileira seja o único senão do tradutor e adaptador Antonio Norival Brito Rabelo. Não encontrei erros no texto; a tradução é muito boa, não senti falta do original. Parabéns.

O livro pretende ser um guia - e alcança este objetivo. Năo concorre com os livros editados, nacionais ou traduzidos, da $\mathrm{APEC}$, da década de 60 e 70 , tal como o de Solomon, M., 